\title{
CBCT Evaluation in a Growing Patient With Mandibular Asymmetry Treated With Rapid Palatal Expander and Frankel-III. Case Report.
}

\section{Monica Macrì ( $\sim$ m.macri@unich.it )}

Gabriele d'Annunzio University of Chieti and Pescara: Universita degli Studi Gabriele d'Annunzio Chieti Pescara https://orcid.org/0000-0002-1068-1319

\section{Fabiola Rendina}

Gabriele d'Annunzio University of Chieti and Pescara: Universita degli Studi Gabriele d'Annunzio Chieti

Pescara

\section{Giada Perrella}

Gabriele d'Annunzio University of Chieti and Pescara: Universita degli Studi Gabriele d'Annunzio Chieti Pescara

\section{Felice Festa}

Gabriele d'Annunzio University of Chieti and Pescara: Universita degli Studi Gabriele d'Annunzio Chieti Pescara

\section{Case report}

Keywords: Facial asymmetry, Dental midline deviation, CBCT, Rapid Palatal Expander, Frankel-III, Orthopedic therapy, Orthodontic therapy

Posted Date: June 16th, 2021

DOl: https://doi.org/10.21203/rs.3.rs-606741/v1

License: (c) (i) This work is licensed under a Creative Commons Attribution 4.0 International License. Read Full License 


\section{Abstract}

\section{Background}

This study aims to evaluate the development and the compensation mechanisms of the mandibular asymmetry in a growing patient, using Cone Beam Computed Tomography (CBCT). In this case, the menton was deviated on the right, an extremely rare condition, which may be the consequence of a disorder in the mandibular growth.

\section{Case presentation}

The patient was treated with Rapid Palatal Expander (RPE) and Fränkel Functional Regulator III (FR-3). The initial CBCT was acquired at the beginning of therapy, when patient was 8 years old (y.o), the final CBCT was acquired at the end of the treatment, when patient was $12 \mathrm{y}$. .o. Patient's CBCT was performed with the head oriented according to the Natural Head Position (NHP); the NHP is a physiological and reproducible posture defined for morphological analysis.

The 3D image of the cranium was oriented in the Dolphin software according to NHP posture; the cephalometric measurements were performed in frontal, laterolateral right and left, posteroanterior and submentovertex views in the aforementioned software.

The therapy lasted 3.8 years and ended with a significant regression of the mandibular asymmetry from moderate grade $(4.2 \mathrm{~mm})$ to slight grade $(1.3 \mathrm{~mm})$.

\section{Conclusion}

The left hemi-mandible has grown more than right side, in accordance with the literature, which affirm that in case of deviation of the menton greater than $4 \mathrm{~mm}$, the bone volume increases on the nondeviated side.

\section{Background}

In medicine, the term "asymmetry" is derived from the Greek word asymmetría and indicates the absence of specularity between the right and left sides of an anatomical part.

Facial asymmetry is defined as the difference in shape, size, position or function between the two sides of the face. [1] In most cases, the asymmetry is not clinically detectable; it is also known as subclinical or minor or normal facial asymmetry [2].

A dominant half-face is recognized in all subjects: in $80 \%$ of cases, it corresponds to the right side, with no differences in distribution according to sex and age [3]. The dominance of the right side is explained by the migration of the cells of the cranial neural crest (NCC): migration begins earlier on the right side than on the left side, but it ends simultaneously on both sides; for this reason, there is an evident 
dominance on the right side of the face; consequently, the menton left-shift (the most inferior point on mandibular symphysis) is more frequent than the right-shift [4].

In addition, the mandibular asymmetry is more frequent than the maxillary asymmetry. In fact, the growth of the maxilla is more stable due to the connection with the cranial base synchondroses and it is less vulnerable to the environmental factors influence; differently, the mandible is the only mobile bone in the skull and for this reason it's highly prone to environmental influences. [5]

The right-shift of the menton is an extremely rare condition which may be the consequence of a disorder in the mandibular growth (i.e. facial trauma, TMJ ankylosis, bad habits, prone sleep position, premature tooth loss, iatrogenic causes, etc.). [6]

The craniofacial growth can be compromised if a pathogenic noxa affects in evolutionary age, producing deformities and asymmetries in the head-neck district.

It's important to detect dento-facial asymmetries in the orthodontic practice: the dental midline is a reference landmark that must coincide with the centre of the mouth (imaginary line that joins the centre of the philtrum with the centre of the palatine raphe). The mandibular midline corresponds to the inferior interincisal line. [7]

\section{Case Report}

This case report evaluates three-dimensional bone development in a male and Caucasian growing patient, with Angle class III malocclusion and mandibular deviation to the right. The orthopedic orthodontic management had a duration of 3.8 years divided into two phases: the first phase with the RPE and the second phase with the FR-3. The patient was 8 y.o. at the beginning of therapy, and he was 12 y.o. at the end. The initial CBCT was acquired at the beginning and the final one at the end of the treatment.

A therapeutic program can be planned for the mandibular asymmetry management after a clinical and radiological diagnosis.

The clinical diagnosis is the first step in orthodontic practice. No systemic pathologies or maxillofacial disorders were found in the medical history; the clinical examination reveals an Angle class III malocclusion, an anterior crossbite and a mandibular midline deviated to the right. The deviation of the lower midline was measured using a ruler and the value was $4 \mathrm{~mm}$.

The radiological diagnosis is the second step: all measurements were performed on the CBCT. The analysis reveals a class I skeletal profile [8] (ANB: $\left.+0.9^{\circ}\right)$, mesocephalic [9] (SN - GoGn: $30.1^{\circ}$ ), hypodivergent growth pattern [10] ( $\left.\mathrm{FH}-\mathrm{GoGn}: 13.6^{\circ}\right)$, moderate right-shift of the menton (4.2 $\left.\mathrm{mm}\right)$ [11].

All CBCT images were obtained with the Planmeca Promax® 3D MID unit (Planmeca Oy, Helsinki, Finland) according to the low-dose protocol with large FOV, normal resolution quality images, $80 \mathrm{kVp}, 5$ 
$\mathrm{mA}$ and acquisition time of $15 \mathrm{~s}$ resulted in a value of effective dose of 35 microSievert ( $\mu \mathrm{Sv})$ [12].

The three-dimensional graphic rendering software used for the cephalometric measurements was Dolphin Imaging 11.95 Premium (Patterson Technology, Chatsworth, CA). The software processes the 3DCT scan images in 2D-DICOM files (Digital Imaging and Communications in Medicine).

Patient's CBCT was performed with the head oriented according to the NHP; the patient was in a sitting position with the back perpendicular to the floor, as much as possible. The head was stabilized with ear rods in the external auditory meatus. The patient was instructed to look into their own eyes in a mirror, 1.5 $\mathrm{m}$ in front of them to obtain NHP. The NHP is a physiological and reproducible posture defined for morphological analysis as described in the orthodontic and anthropological literature. [13]

The 3D image of the cranium was oriented in the Dolphin software according to NHP posture, before taking cephalometric measurements.

The NHP orientation was carried out by the widgets present in Dolphin; hard and soft tissue views were checked for orientation in the software by visualizing head from front, right, and left sides. In the NHP there are 3 reference planes (Fig. 1), perpendicular to each other, which are identified on the software for the patient's cephalometric measurements.

1. The transverse plane coincides with the Frankfurt plane $(\mathrm{FH})$, a plane passing through two points: Orbital (Or) and Porion (Po);

2. The sagittal plane coincides with the mid-sagittal plane (MSP), a plane perpendicular to the plane FH and passing through two points: Crista galli $(\mathrm{Cg})$ and Basion $(\mathrm{Ba})$;

3. The coronal plane coincides with the anteroposterior (PO) plane, perpendicular to the FH and MSP, passing through the right and left porion.

The reference landmarks used for cephalometric measurements are described in Table 1 
Table 1

Reference cephalometric landmarks

\begin{tabular}{|c|c|c|}
\hline Landmark & Abbreviation & Description \\
\hline Crista galli & $\mathrm{Cg}$ & The most superior point of the crista galli of the ethmoid bone \\
\hline Basion & $B a$ & $\begin{array}{l}\text { The median point on the anterior margin of the foramen } \\
\text { magnum }\end{array}$ \\
\hline Porion & Po & The highest point on the roof of the external auditory meatus \\
\hline Orbitale & Or & The deepest point on the infraorbital margin \\
\hline Condylion superius & Cdsup & The most superior point of the condyle head \\
\hline Condylion medialis & Cdmed & The most medial point of the condyle head \\
\hline Condylion lateralis & Cdlat & The most lateral point of the condyle head \\
\hline $\begin{array}{l}\text { Condylion } \\
\text { posterius }\end{array}$ & Cdpost & The most posterior point of the condyle head \\
\hline Sigmoid notch & $S$ & The most inferior point of sigmoid notch \\
\hline Gonion lateralis & Golat & The most lateral point of the gonion area \\
\hline Gonion posterius & Gopost & The most posterior point of the gonion area \\
\hline Gonion inferius & Goinf & The most inferior point of the gonion area \\
\hline Menton & Me & The most inferior point on mandibular symphysis \\
\hline $\begin{array}{l}\text { First maxillary } \\
\text { molar }\end{array}$ & 6 & Occlusal fossa of the maxillary first molar \\
\hline Mandibular canine & 3 & Cuspal tip of the mandibular canine \\
\hline
\end{tabular}

The CBCT measurements (Table 2) were performed in frontal, laterolateral right, laterolateral left, posteroanterior and submentovertex views. Each measurement was performed on the initial and final CBCT. Also, the size of the right and left masseter muscles was evaluated with widget present in Dolphin. In frontal view, the size of each muscle was measured by adjusting the translucency instrument, to discriminate soft from hard tissues. 
Table 2

Cephalometric measurements

Landmarks
Pre-treatment
Post-treatment

Results
FRONTAL VIEW (F)

Menton deviation

Right masseter muscle
Distance from

Me to MSP

Maximum length

and width
$4.2 \mathrm{~mm}$

(moderate

deviation)

Lenght: 55.4

$\mathrm{mm}$

Width: 15.7

$\mathrm{mm}$

Maximum length

and width
Lenght: 51.0

$\mathrm{mm}$

Width: 11.3

$\mathrm{mm}$
$1.3 \mathrm{~mm}$ (slight

deviation)

$\Delta:-2.9$

$\mathrm{mm}$

Lenght 61.5

$\mathrm{mm}$

$\Delta:+6.1$

$\mathrm{mm}$

Width: 19.4

$\mathrm{mm}$

$\Delta:+3.7$

$\mathrm{mm}$

Lenght 54.3

$\mathrm{mm}$

$\Delta:+3.3$

$\mathrm{mm}$

Width: 14.9

$\Delta:+3.6$

$\mathrm{mm}$

$\mathrm{mm}$

\section{LATEROLATERAL VIEW (LL)}

Vertical facial growth pattern

Frankfort-mandibular plane angle (FMA)

Sagittal facial growth pattern (ANB)

Right-left difference in lateral ramal inclination;
Angle from $\mathrm{SN}$ to GoGn

Angle from $\mathrm{FH}$ to GoGn

Angle from $A$ to $\mathrm{N}$ to $\mathrm{B}$

Angle from $\mathrm{Cd}$ post - Go post to $\mathrm{FH}$ $30.1^{\circ}$

(mesofacial)

$13.6^{\circ}$

(hypodivergent)

$0.9^{\circ}$ (class I)

Right: $74.7^{\circ}$

Left: $73.4 \mathrm{~mm}$ sX
Distance from

Copost gopost

Right: $37.7 \mathrm{~mm}$
Left: $33.8 \mathrm{~mm}$ length (without condyle and gonial angle)

Right left difference in ramus $32.5^{\circ}$

(mesofacial)

$16.8^{\circ}$

(hypodivergent)

$2.5^{\circ}$ (class I)

$\Delta:+1.6^{\circ}$

$\Delta:+2.4^{\circ}$

$\Delta:+3.2^{\circ}$

Right: $77.1^{\circ}$

$\Delta:+2.4^{\circ}$

Left: $71.8^{\circ}$

$\Delta:-1.6^{\circ}$

$\begin{array}{lllll}\text { gonial angle) } & \text { Left: } 33.8 \mathrm{~mm} & \text { Left: } 41.6 \mathrm{~mm} & \begin{array}{l}\Delta:+7.8 \\ \mathrm{~mm}\end{array} \\ \begin{array}{l}\text { Right-left difference in ramus } \\ \text { length (with condyle and } \\ \text { gonial angle) }\end{array} & \begin{array}{l}\text { Distance from } \\ \text { Cdsup to Go inf }\end{array} & \begin{array}{l}\text { Right: } 50.9 \mathrm{~mm} \\ \text { Left: } 48.9 \mathrm{~mm}\end{array} & \begin{array}{c}\text { Right: } 55.8 \mathrm{~mm} \\ \text { Left: } 54.6 \mathrm{~mm}\end{array} & \begin{array}{l}\Delta:+4.9 \\ \mathrm{~mm}\end{array} \\ & & & \begin{array}{l}\Delta:+5.7 \\ \mathrm{~mm}\end{array}\end{array}$




\begin{tabular}{|c|c|c|c|c|}
\hline & Landmarks & Pre-treatment & Post-treatment & Results \\
\hline \multirow[t]{2}{*}{$\begin{array}{l}\text { Right-left difference in } \\
\text { condylar height }\end{array}$} & \multirow{2}{*}{$\begin{array}{l}\text { Distance from } \\
\text { Cdsup to S }\end{array}$} & Right: 18.3 mm & Right: 17.3 mm & $\begin{array}{l}\Delta:-1.0 \\
\mathrm{~mm}\end{array}$ \\
\hline & & Left: $18.1 \mathrm{~mm}$ & Left: 20.2 mm & $\begin{array}{l}\Delta:+2.1 \\
\mathrm{~mm}\end{array}$ \\
\hline \multicolumn{5}{|l|}{ POSTERO-ANTERIOR VIEW (PA) } \\
\hline \multirow{2}{*}{$\begin{array}{l}\text { Right-left difference in } \\
\text { maxillary height }\end{array}$} & \multirow[t]{2}{*}{6 to $\mathrm{FH}$} & Right: $29.0 \mathrm{~mm}$ & Right: 35.8 mm & \multirow{2}{*}{$\begin{array}{l}\Delta:+6.8 \\
\mathrm{~mm} \\
\Delta:+9.8 \\
\mathrm{~mm}\end{array}$} \\
\hline & & Left: 27.2 mm & Left: 37.0 mm & \\
\hline \multirow{2}{*}{$\begin{array}{l}\text { Right-left difference in frontal } \\
\text { ramal inclination }\end{array}$} & \multirow{2}{*}{$\begin{array}{l}\text { Angle from } \\
\text { Cdlat-Golat to } \\
\text { MSP }\end{array}$} & Right: $20.4^{\circ}$ & Right: $14.9^{\circ}$ & $\Delta:-5.5^{\circ}$ \\
\hline & & Left: $16.5^{\circ}$ & Left: $16.9^{\circ}$ & $\Delta:+0.5^{\circ}$ \\
\hline \multirow{2}{*}{$\begin{array}{l}\text { Right-left difference in } \\
\text { mandibular body height }\end{array}$} & \multirow{2}{*}{$\begin{array}{l}\text { Distance from } 3 \\
\text { to GoGn }\end{array}$} & \multirow{2}{*}{$\begin{array}{l}\text { Permanent } \\
\text { canines not } \\
\text { erupted }\end{array}$} & Right: $53.1 \mathrm{~mm}$ & \multirow{2}{*}{$\begin{array}{l}\text { Not } \\
\text { evaluable }\end{array}$} \\
\hline & & & Left: 33.3 mm & \\
\hline Intercondilar distance & $\begin{array}{l}\text { Distance from } \\
\text { right Cdmed to } \\
\text { left Cdmed }\end{array}$ & $74.0 \mathrm{~mm}$ & $83.3 \mathrm{~mm}$ & $\begin{array}{l}\Delta:+9.3 \\
\mathrm{~mm}\end{array}$ \\
\hline Extracondilar distance & $\begin{array}{l}\text { Distance from } \\
\text { right Cdlat to left } \\
\text { Cdlat }\end{array}$ & 102.7 mm & $107.9 \mathrm{~mm}$ & $\begin{array}{l}\Delta:+5.2 \\
\mathrm{~mm}\end{array}$ \\
\hline $\begin{array}{l}\text { Maximum width of the left } \\
\text { condyle }\end{array}$ & $\begin{array}{l}\text { Distance from } \\
\text { Cdlat to Cdmed }\end{array}$ & $15.0 \mathrm{~mm}$ & $16.1 \mathrm{~mm}$ & $\begin{array}{l}\Delta:+1.1 \\
\mathrm{~mm}\end{array}$ \\
\hline $\begin{array}{l}\text { Maximum width of the right } \\
\text { condyle }\end{array}$ & $\begin{array}{l}\text { Distance from } \\
\text { Cdlat to Cdmed }\end{array}$ & $15.1 \mathrm{~mm}$ & $16.5 \mathrm{~mm}$ & $\begin{array}{l}\Delta:+1.4 \\
\mathrm{~mm}\end{array}$ \\
\hline \multirow{2}{*}{$\begin{array}{l}\text { Right-left difference in } \\
\text { condyle - MSP distance }\end{array}$} & \multirow{2}{*}{$\begin{array}{l}\text { Distance from } \\
\text { Cdlat to MSP }\end{array}$} & Right: 50.3 mm & Right: 51.7 mm & \multirow{2}{*}{$\begin{array}{l}\Delta:+1,4 \\
\mathrm{~mm} \\
\Delta:+1,5 \\
\mathrm{~mm}\end{array}$} \\
\hline & & Left: 52.3 mm & Left: $53.8 \mathrm{~mm}$ & \\
\hline \multicolumn{5}{|l|}{ SUB-MENTOVERTEX VIEW (SMV) } \\
\hline \multirow{2}{*}{$\begin{array}{l}\text { Right-left difference in } \\
\text { mandibular body length; }\end{array}$} & \multirow[t]{2}{*}{ Me-Gopost, } & Right: 76.4 mm & Right: 77.4 mm & $\begin{array}{l}\Delta:+1 \\
\mathrm{~mm}\end{array}$ \\
\hline & & Left: 74.9 mm & Left: 82.4 mm & $\begin{array}{l}\Delta:+7.5 \\
m m\end{array}$ \\
\hline
\end{tabular}

\section{Discussion}


The orthopedic therapy was performed in two phases: the first phase with rapid palatal expander (RPE), the second phase with the Fränkel function regulator III (FR-3).

The first phase of the treatment consists in the use of the RPE which provides a transverse expansion of the maxilla; the RPE was initially activated on the chair by performing a full turn of the screw, which corresponds to 4 activations $(1 \mathrm{~mm})$. The patient was instructed to activate the RPE at home, twice a day ( $0.5 \mathrm{~mm}$ expansion a day), for 10 days. The appliance was removed after 6 months after its last activation.

The second phase with the FR-3 provided correction of skeletal deformities and prognathism. The therapeutic principle is based on the elimination of all factors that could arrest the maxillary development and at the same time prevent excessive mandibular growth. [14]

A partial recentering of the mandibular midline was achieved ( $2.9 \mathrm{~mm}$ to the left), as confirmed by CBCT; however; at the end of the therapy, the menton was still deviated $1.2 \mathrm{~mm}$ to the right (slight deviation) [15].

The increased ANB angle shows that point A advanced sagittally more than point $B$, therefore the maxilla has grown more than the mandible.

The left hemi-mandible has grown more than the right one as well as the height of the left half-maxilla compared to the right one. The increase in bone volume on the non-deviated side is due to the compensation mechanisms that occur when the deviation of the menton is greater than $4 \mathrm{~mm}$. [16]

In specific, the most important vertical growth of bone occurs at the level of the left mandibular ramus; therefore, also the condyle and the goniac angle on the left side have grown more than the right side.

The growth of the left hemi-mandible was also confirmed by measuring inclination of the left ramus external border: the angle with MSP decreased in opposition to the right side which was slightly increased, proving a strong growth of bone in the transverse direction on the left hemi-mandible, also confirmed by the SMV view.

\section{Conclusions}

The growing patient with moderate right menton deviation was successfully treated with the use of RPE and FR-3. There was a significant regression of the mandibular asymmetry from moderate grade (4.2 $\mathrm{mm}$ ) to slight grade $(1.3 \mathrm{~mm})$, in addition to the correction of dental characteristics (dental class III and anterior crossbite). These therapeutic goals are the result of a compensation mechanism: the left hemimandible has grown more than right side, in accordance with the literature which affirm that in case of deviation of the menton greater than $4 \mathrm{~mm}$, the bone volume increases on the nondeviated side.

\section{Declarations}




\section{Ethical Approval and Consent to participate}

The study was performed in the Oral Sciences Department of the University of Chieti G. D'Annunzio. Ethics approval (number 23) was obtained by the hospital's Independent Ethics Committee of Chieti. The study protocol was drawn in accordance with the European Union Good Practice Rules and with the Helsinki Declaration. Written informed consent was obtained from the patient for publication of this report and any accompanying images.

\section{Consent for publication}

All authors read and approved the final manuscript and give their consent for publication.

\section{Availability of data and materials}

The datasets used and/or analysed during the current study are available from the corresponding author on reasonable request.

\section{Competing interests}

The authors declare that they have no competing interests.

\section{Funding}

University Gabriele D’Annunzio of Chieti, Italy.

\section{Authors' contributions}

FF,MM orthodontic performed and documented the case. FR, MM: conducted a review of literature and drafted the manuscript. GP,FF,MM: exams performed the analysis of the CBCT images.

\section{Acknowledgements}

"Not applicable".

\section{References}

1. Ercan I, Ozdemir ST, Etoz A, Sigirli D, Tubbs RS, Loukas M, Guney I. Facial asymmetry in young healthy subjects evaluated by statistical shape analysis. Journal of Anatomy. 2008 Dec;213(6):663- 
9.

2. Thiesen G, Gribel BF, Freitas MP. Facial asymmetry: a current review. Dental press journal of orthodontics. 2015 Dec;20(6):110-25.

3. Hafezi F, Javdani A, Naghibzadeh B, Ashtiani AK. Laterality and left-sidedness in the nose, face, and body: a new finding. Plastic and Reconstructive Surgery Global Open. 2017 Dec;5(12).

4. Geschwind N, Galaburda AM. Cerebral lateralization: Biological mechanisms, associations, and pathology: II. A hypothesis and a program for research. Archives of neurology. 1985 Jun 1;42(6):52152.

5. Haraguchi S, Iguchi Y, Takada K. Asymmetry of the face in orthodontic patients. The Angle Orthodontist. 2008 May;78(3):421-6.

6. Liu MT, Iglesias RA, Sekhon SS, Li Y, Larson K, Totonchi A, Guyuron B. Factors contributing to facial asymmetry in identical twins. Plastic and reconstructive surgery. 2014 Oct 1;134(4):638-46.

7. Nold SL, Horvath SD, Stampf S, Blatz MB. Analysis of select facial and dental esthetic parameters. Int J Periodontics Restorative Dent. 2014 Sep 1;34(5):623-9.

8. Gasgoos SS, Al-Saleem NA, Awni K. Cephalometric features of skeletal Class I, II and III (A comparative study). Al-Rafidain Dental Journal. 2007 Jun 1;7(2):122-30.

9. Franco FC, Araujo TM, Vogel CJ, Quintão CC. Brachycephalic, dolichocephalic and mesocephalic: Is it appropriate to describe the face using skull patterns?. Dental press journal of orthodontics. 2013 Jun;18(3):159-63.

10. DiPietro GJ, Moergeli Jr JR. Significance of the Frankfort-mandibular plane angle to prosthodontics. The Journal of prosthetic dentistry. $1976 \mathrm{Dec}$ 1;36(6):624-35.

11. Haraguchi, S., Takada, K., \& Yasuda, Y. (2002). Facial asymmetry in subjects with skeletal Class III deformity. The Angle Orthodontist, 72(1), 28-35.

12. Feragalli B, Rampado O, Abate C, Macrì M, Festa F, Stromei F, Caputi S, Guglielmi G. Cone beam computed tomography for dental and maxillofacial imaging: technique improvement and low-dose protocols. La radiologia medica. 2017 Aug;122(8):581-8.

13. Festa F, Pagnoni M, Valerio R, Rodolfino D, Saccucci M, d’Attilio M, Caputi S, lannetti G. Orbital volume and surface after Le Fort III advancement in syndromic craniosynostosis. Journal of Craniofacial Surgery. 2012 May 1;23(3):789-92.

14. Fränkel R. A functional approach to orofacial orthopaedics. British Journal of Orthodontics. 1980 Jan;7(1):41-51.

15. Gribel BF, Thiesen G, Borges TS, Freitas MP. Prevalence of mandibular asymmetry in skeletal Class I adult patients. Journal of Research in Dentistry. 2014 May 3;2(2):189-97.

16. Kim SJ, Lee KJ, Lee SH, Baik HS. Morphologic relationship between the cranial base and the mandible in patients with facial asymmetry and mandibular prognathism. American Journal of Orthodontics and Dentofacial Orthopedics. 2013 Sep 1;144(3):330-40. 


\section{Figures}
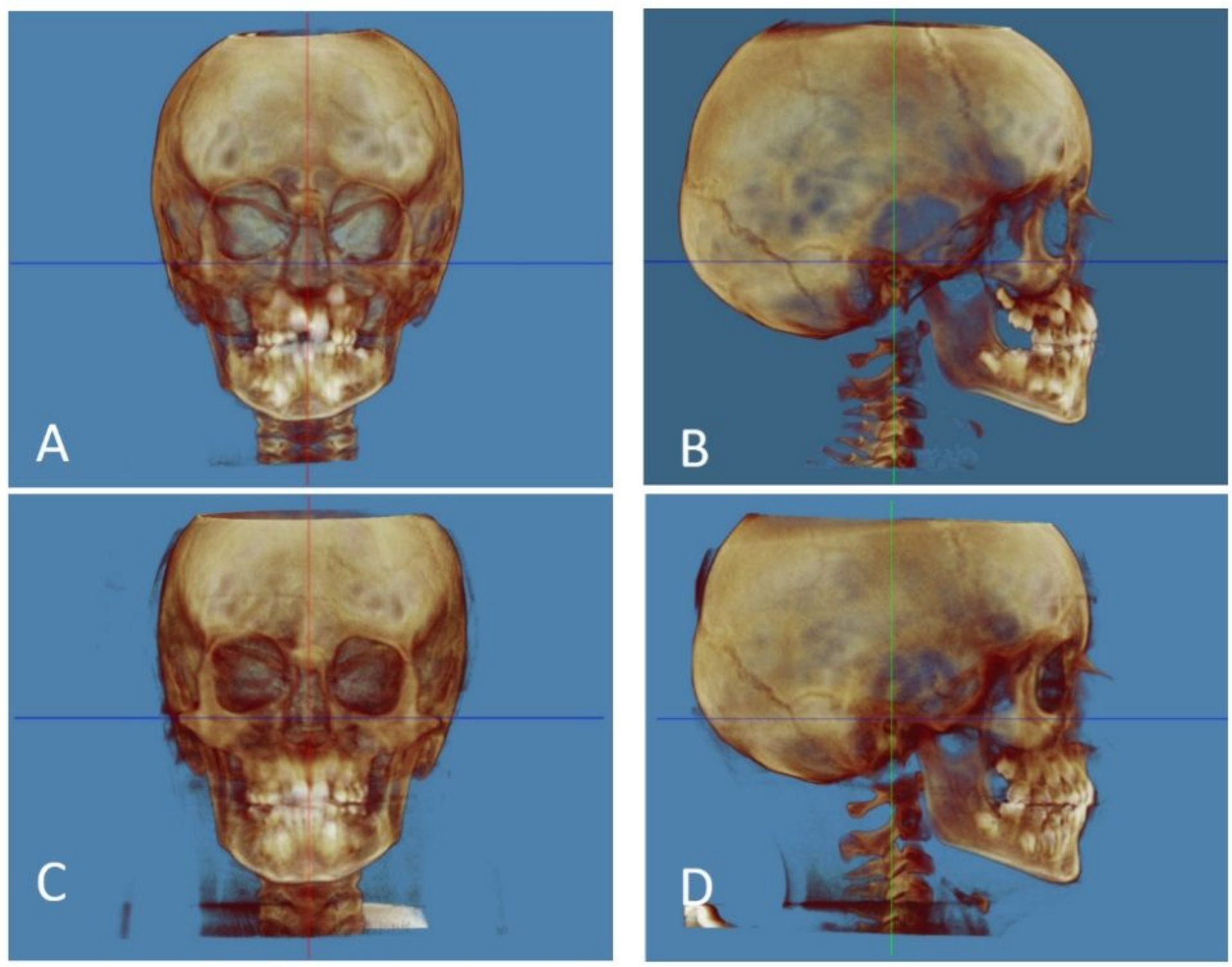

\section{Figure 1}

$\mathrm{CBCT}$ images. A. Pre-treatment frontal view; B. pre-treatment lateral view (right); C. Post-treatment frontal view; D. Post-treatment lateral view (right). The red line corresponds to Sagittal Plane. The green line corresponds to Coronal Plane. The blue line corresponds to Transverse Plane. 